Please share your stories about how Open Access to this article benefits you.

\title{
Effects of tone on the three-way laryngeal distinction in Korean: An acoustic and aerodynamic comparison of the Seoul and South Kyungsang dialects
}

by Hyunjung Lee and

Allard Jongman

2012

This is the published version of the article, made available with the permission of the publisher. The original published version can be found at the link below.

Lee, H., and Jongman, A. (2012). Effects of tone on the three-way laryngeal distinction in Korean: An acoustic and aerodynamic comparison of the Seoul and South Kyungsang dialects. Journal of the International Phonetic Association 42, 145-169.

Published version: http://dx.doi.org/10.1017/Soo25100312000035

Terms of Use: http://www2.ku.edu/ scholar/docs/license.shtml 


\title{
Effects of tone on the three-way laryngeal distinction in Korean: An acoustic and aerodynamic comparison of the Seoul and South Kyungsang dialects
}

\author{
Hyunjung Lee
}

University of Kansas

hyunjung@ku.edu

Allard Jongman

University of Kansas jongman@ku.edu

The three-way laryngeal distinction among voiceless Korean stops has been well documented for the Seoul dialect. The present study compares the acoustic and aerodynamic properties of this stop series between two dialects, non-tonal Seoul and tonal South Kyungsang Korean. Sixteen male Korean speakers (eight from Seoul and eight from Kyungsang) participated. Measures collected included VOT, f0 at vowel onset, H1-H2, and air pressure and airflow. The presence versus absence of lexical pitch accent affects both the acoustic and aerodynamic properties. First, Seoul speakers use a combination of f0 and VOT to distinguish the three-way contrast of Korean stops, while Kyungsang speakers mainly use VOT. Second, the presence of lexical pitch for Kyungsang speakers makes f0 an unreliable acoustic cue for the three Korean stops. Third, dialectal differences in VOT to mark the three-way distinction support the notion of a diachronic transition whereby VOT differences between the lenis and aspirated stops in Seoul Korean have been decreasing over the past 50 years. Finally, the aerodynamic results make it possible to postulate the articulatory state of the glottis, indicating a positive correlation with acoustic parameters. Based on the acoustic and aerodynamic results, phonological representations of Korean stops for the tonal and non-tonal dialects are suggested.

\section{Introduction}

Unlike most of world's languages, which have a two-way distinction among voiceless stops, Korean has a three-way laryngeal distinction among voiceless stops (called fortis, lenis, aspirated) in word-initial or phrase-initial position, and these three stops occur at three places of articulation (bilabial, alveolar, velar). This unusual three-way stop contrast has been intensively investigated for the past five decades in the fields of acoustics, perception and articulation. The investigation of this stop series, however, has been mostly done 
for the non-tonal Seoul dialect (standard Korean), and few studies have been conducted for tonal dialects of Korean. The purpose of this study is to examine and compare the acoustic and aerodynamic properties of the Korean stops between two dialects, non-tonal Seoul and tonal South Kyungsang Korean, focusing on the effects of tone on the threeway stop distinction. Through the direct comparison of the acoustic and aerodynamic characteristics for the three-way contrast of Korean stops between these two dialects, we hope to gain a deeper understanding of segmental distinctions and their interaction with tone.

Previous research on Korean stops (e.g. Lisker \& Abramson 1964, C.-W. Kim 1965, Cho, Jun \& Ladefoged 2002) agrees that the consonant durational property of VOT is one of the main acoustic cues to classify Korean stops, reporting that the mean VOT is longest for the aspirated stop, intermediate for the lenis stop, and shortest for the fortis stop. However, overlap of VOT values for the fortis and lenis and the lenis and aspirated stops suggests that VOT alone cannot perfectly distinguish the three stops. Although VOT can reliably distinguish the fortis stop from the aspirated stop, it is less clear whether VOT can differentiate the lenis stop from the other two stops, questioning the validity of VOT as the single acoustic cue. A number of subsequent acoustic and perception studies (e.g. C.-W. Kim 1965, 1970; Han \& Weitzman 1970; Cho 1996; Choi 2002; M.-R. Kim, Beddor \& Horrocks 2002) have revealed that properties of the following vowel after the stop release are also primary acoustic cues along with VOT of the stop segments themselves. Specifically, the fundamental frequency (f0) of the onset of the following vowel also plays a role in making the stop distinction, with the lowest value of $\mathrm{fo}$ for the lenis stop, and a relatively high value of $\mathrm{fo}$ for the aspirated and fortis stops in the following vowel. In the previous research, the comparison of $\mathrm{f} 0$ in the following vowel between the fortis and aspirated stops reveals slightly higher f0 values after the aspirated stop than after the fortis stop, although there is some overlap. To sum up, f0 distinguishes Korean lenis stops from the aspirated and fortis stops, and distinguishing the three-way Korean stop contrast does not rely on a single acoustic cue, but VOT and f0 both contribute to the stop distinction.

Along with $\mathrm{fo}$ in the following vowel, the phonation type of the following vowel has also been examined by measuring the amplitude difference between the first harmonic (H1) and the second harmonic (H2) (e.g. Ahn 1999, Cho et al. 2002, Kang \& Guion 2008). However, there is disagreement among several studies. Specifically, while Cho et al. (2002) reported the lowest and the highest value of $\mathrm{H} 1-\mathrm{H} 2$ after the fortis stop and the lenis stop, respectively, Ahn (1999) and Kang \& Guion (2008) reported the lowest value for the fortis stop, but the highest value for the aspirated stop. Ahn (1999) and Kang \& Guion (2008) suggested that the low (or negative) H1-H2 value after the fortis stop indicated a more pressed or creaky voice while the high $\mathrm{H} 1-\mathrm{H} 2$ values after the aspirated stop indicated breathy voice.

Aerodynamic studies measuring air pressure and airflow have also been conducted to provide information on the subglottal and supraglottal systems of the distinctive Korean stops. Dart (1987) measured intraoral air pressure (Po) and airflow (Uo) of Korean fortis and lenis bilabial stops in word-initial position. Dart (1987) reported that despite individual variation, lenis stops showed greater airflow, but lower air pressure. In contrast, the fortis stop was reported as having less airflow, but greater air pressure. By means of computer modeling, Dart (1987) tested the hypothesis that the difference in airflow is caused by differences in VOT, and the difference in air pressure comes from the tension of the vocal folds or subglottal state. Glottal area function, vocal tract wall tension, respiratory muscle force, and supraglottal cavity volume were simulated following the reported values of glottal opening, VOT values or vocal tract wall tension in previous studies for Korean fortis and lenis stops. Based on the observed values and aerodynamic modeling, Dart (1987) suggested that the unbalanced pattern of intraoral airflow and air pressure for fortis stops stemmed from the adducted vocal folds before release, indicating more tensed vocal folds and heightened subglottal pressure for fortis stops. 

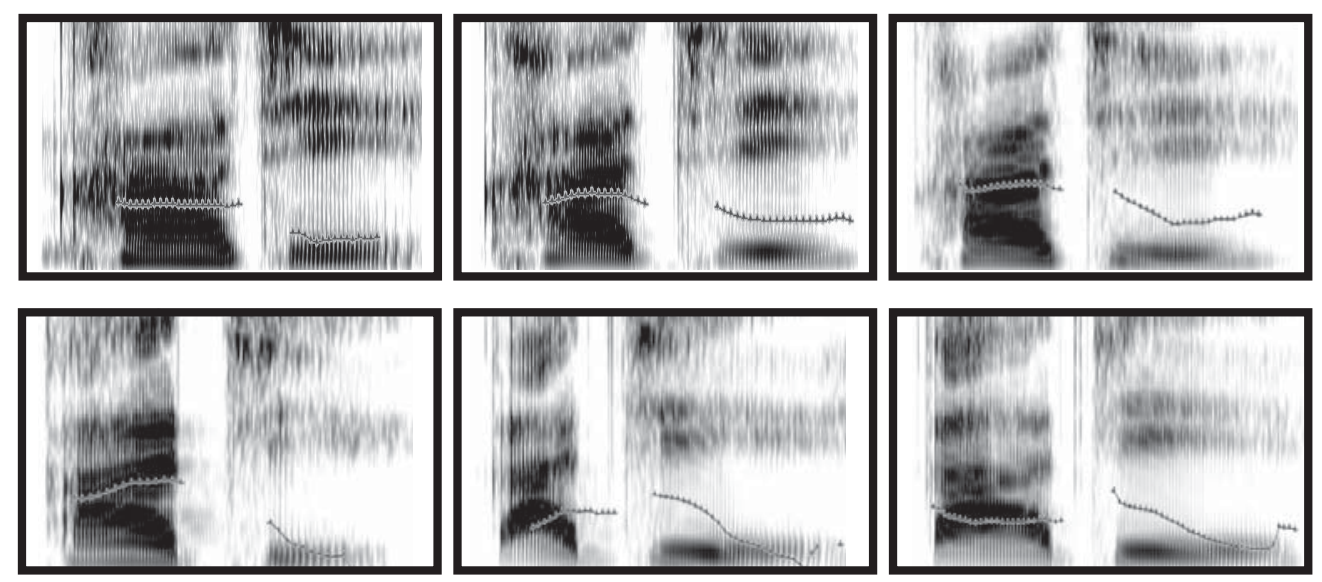

Figure 1 Spectrograms of káci (HL) 'n. kind', kácí (HH) 'branch', and kàcí (LH) 'eggplant' from a female Seoul (top row) and a female South Kyungsang speaker (bottom row).

Cho et al. (2002) also examined the aerodynamic properties of Korean stops in two dialects, Seoul and Cheju Korean, an endangered Korean language. Unlike Dart's study, this study included all three stop categories and measured intraoral air pressure and intraoral airflow of Korean bilabial stops. Cho et al. (2002) reported that the maximum oral pressure during the stop closure was smaller for the lenis stop than for the fortis and aspirated stops, while the maximum air pressure rate for the fortis and aspirated stops was comparable. For the intraoral airflow, the fortis stop showed a smaller airflow rate than the lenis stop, which is in line with Dart (1987). Based on these results and Dart's aerodynamic model, Cho et al. (2002) suggested that 'an increase in subglottal pressure due to an increase in respiratory effort is the cause of the higher oral pressure in fortis stops' (Cho et al. 2002: 210). The researchers proposed that the stiffened vocal tract wall and smaller glottal area might cause the decrease in velocity of airflow in fortis stops, which accounts for the low airflow rate for the fortis stop. In addition, the glottal impedance with constricted vocal folds might lower the oral pressure in the fortis stop as compared to aspirated stop. For the aspirated stop, Cho et al. (2002) posited that the large glottal area at the stop release might cause the greater oral airflow and pressure.

Several acoustic studies have investigated the Korean stops across dialects (e.g. Cho et al. 2002, Choi 2002, Kenstowicz \& Park 2006). A recent study by Kenstowicz \& Park (2006) examined the three-way laryngeal contrast of stops in tonal dialects, namely the Kyungsang dialects. Unlike most Korean dialects, which have lost their lexical pitch accent contrasts from Middle Korean, the lexical pitch accent system has been preserved in the North and South Kyungsang dialects of Korean (spoken in the south eastern part of the Korean peninsula; e.g. Ramsey 1975). In a pitch accent language, each phonological word has at least one high pitch prominence and the difference in location of the high pitch leads to a difference in meaning. In disyllables, for example, Kyungsang dialects distinguish triplets using three contrastive pitch accent patterns as in káci (HL) 'n. kind', kácí (HH) 'branch', and kàcí (LH) 'eggplant'. In contrast, for Seoul Korean speakers who do not use pitch differences for lexical distinctions, these triplets are homophones. Figure 1 shows spectrograms of the three contrastive pitch accent patterns in South Kyungsang Korean compared to Seoul Korean.

As mentioned earlier, previous research on Korean stops has shown that f0 primarily cues the Korean stops along with VOT. Accordingly, Kenstowicz \& Park (2006) examined the acoustic properties of stops in Kyungsang Korean, including VOT, H1-H2 as well as f0. Since M. Kim \& Duanmu (2004) had analyzed the lenis stop as underlyingly voiced because 
it becomes voiced in intervocalic position, Kenstowicz \& Park (2006) specifically focused on the effect of the underlying voicing of the preceding consonant on the high vs. low tonal contrast in the following vowel. One of the main findings in Kenstowicz \& Park (2006) is that f0 after underlying voiceless consonants such as fortis and aspirated stops is relatively high, compared to that of underlying voiced consonants such as lenis and nasal consonants in the Kyungsang dialects; this was true for both high and low tonal conditions. Such f0 differences due to the voicing of the preceding consonants have been noted for a variety of languages, including English, French and Taiwanese (e.g. Hombert \& Ladefoged 1977, Lai 2004). Kenstowicz \& Park (2006) reported that the average onset f0 value after lenis and nasal consonants (underlying voiced consonants) is about $210 \mathrm{~Hz}$ (from female speakers), and the onset f0 value after fortis and aspirated stops (underlying voiceless consonants) is about $240 \mathrm{~Hz}$. In addition, the researchers compared the High vs. Low tonal contrasts at vowel onset and midpoint in the initial syllable to see how well the two tonal contrasts were separated. Kenstowicz \& Park (2006) reported that the onset f0 of a high tone vowel after the fortis and aspirated stop and the onset f0 of a low tone vowel after the lenis stop are clearly separated from each other, while the onset $\mathrm{f0}$ of a low tone vowel after the fortis and aspirated stop and the onset $\mathrm{f} 0$ of a high tone vowel after the lenis stop overlapped considerably. In other words, in terms of f0, the low tone fortis or the low tone aspirated stop is not distinguishable from the high tone lenis stop. Unlike the non-tonal Seoul dialect where f0 reliably distinguishes the lenis from the fortis and the aspirated stop, the presence of lexical pitch in the Kyungsang dialect questions the role of $\mathrm{f} 0$ as a cue to distinguish the three contrastive stops. Consequently, Kenstowicz \& Park (2006) suggested H1-H2 as a compensating factor for the reduced role of f0, particularly between the fortis and lenis stops in Kyungsang Korean. This suggestion was based on the greater H1-H2 difference between the fortis and lenis stops in Kyungsang than in the Seoul Korean data reported by Cho et al. (2002).

While a great number of studies have investigated the unusual three-way distinction of Korean stops, only a few studies have focused on the effect of the lexical pitch accent contrast. Importantly, to the best of our knowledge, a direct dialectal comparison between non-tonal Seoul and tonal Kyungsang has not been conducted for the three-way laryngeal distinction among Korean voiceless stops. Although the recent study by Kenstowicz \& Park (2006) addressed the questionable role of f0 in the three-way distinction among Korean stops in tonal Kyungsang Korean, there is one drawback that makes it difficult to confirm the authors' conclusions. Specifically, Kenstowicz \& Park (2006) limited their investigation of the Korean stops to Kyungsang Korean. The dialectal comparison between Seoul and Kyungsang Korean was made across two different studies: Kyungsang data from the authors themselves and Seoul data from Cho et al. (2002). The dialectal comparison of acoustic measures across two different studies is not the best way to address the role of lexical pitch in the three-way stop distinction. First, differences in methodology can be a confounding factor. Kenstowicz \& Park (2006) used both different stimuli and different contexts than Cho et al. (2002). Kenstowicz \& Park (2006) recorded stimuli in sentential frames, but Cho et al. (2002) used words in isolation. Kenstowicz \& Park (2006) obtained smaller VOT differences between the lenis and aspirated stops for Kyungsang than those for Seoul Korean reported in Cho et al. (2002). As noted by Kenstowicz \& Park (2006) themselves, however, the different stimulus contexts may have resulted in different acoustic findings (Kenstowicz \& Park 2006: 4). Accordingly, it remains unclear whether the smaller VOT difference between the lenis and aspirated stops was due to dialectal or methodological differences. In this sense, the difference in methodology makes it hard to directly connect any acoustic differences between Seoul and Kyungsang Korean to the dialectal difference. Consequently, it is hard to argue that the difference between the two dialects is because of the difference in their tonal systems.

Second, the combination of data from two different studies makes a statistical evaluation impossible. The lack of crucial comparisons regarding dialect effects (i.e. main effect of dialect or interactions of stops by dialect) makes it impossible to draw any conclusion regarding the role of lexical tone. For example, Kenstowicz \& Park (2006) suggested H1-H2 as a possible 
compensating factor for $\mathrm{f} 0$ based on the larger $\mathrm{H} 1-\mathrm{H} 2$ difference among stops in Kyungsang than in Seoul Korean. However, this suggestion was based on a 'numerical' comparison between Cho et al. (2002) and their findings, that is, without evaluating an interaction effect of the three-way distinction by dialect. Consequently, the suggestion of $\mathrm{H} 1-\mathrm{H} 2$ as a compensating factor merely remains a speculation, and it is still unclear whether the presence of lexical pitch in Kyungsang has anything to do with a potential dialect difference in H1-H2.

The present research is an attempt to remedy this situation by minimizing potential variation that might be caused by methodological differences as well as by conducting systematic inferential statistics. The current study provides a comprehensive comparison of the three-way laryngeal distinction among stops in a non-tonal (Seoul) and a tonal (South Kyungsang) dialect of Korean. Through this direct dialect comparison, the current paper aims to provide an analysis of the effect of pitch accent on segmental distinctions as well as replicate previous findings in each dialect. Broadly, the present study aims to address the questions of (i) how the presence of lexical pitch in Kyungsang Korean affects the threeway laryngeal distinction, and (ii) how multiple acoustic cues play a role in categorizing the Korean stops in the two dialects with different tonal systems. Specifically, the paper explores which other cues make up for the weakened role of f0 in Kyungsang Korean if f0 is unsuccessful in distinguishing the three stops as reported by Kenstowicz \& Park (2006). In addition, if the acoustic parameters for the three-way laryngeal distinction pattern differently in Seoul and South Kyungsang Korean, is this because of the different tonal system between the two dialects? We hypothesize that if $\mathrm{f} 0$ of the three-way laryngeal distinction patterns differently in the two dialects, other acoustic parameters such as VOT and $\mathrm{H} 1-\mathrm{H} 2$ would also pattern differently by showing significant interaction effects between the three-way laryngeal distinction and dialect. As noted by Repp (1983) for speech perception, multiple cues work together to signal phonemic contrasts, and these cues trade with each other in terms of their importance. In this sense, the current study may speculate that if f0 is not sufficiently distinctive in South Kyungsang Korean compared to Seoul Korean due to the fact that f0 in Kyungsang serves to contrast pitch accents as well as laryngeal distinctions, the importance of other cues such as VOT and H1-H2 will increase. Contrary to Kyungsang Korean, Seoul Korean, in which f0 is only a cue for the three-way stop distinction, may be hypothesized to rely more on f0 than Kyungsang Korean, while the role of other cues such as VOT and H1-H2 will not be as great as in Kyungsang Korean. Therefore, it is predicted that f0 as well as other cues such as VOT and H1-H2 will pattern differently for the three-way stop distinction between the two dialects.

Along with the acoustic study, the current study also examines aerodynamic properties by measuring intraoral airflow (Uo) and intraoral air pressure (Po) in non-tonal Seoul and tonal Kyungsang Korean. Measures of the intraoral air pressure and airflow indicate the subglottal and supraglottal systems, including information on vocal fold tension, subglottal pressure, and glottal area. Importantly, no aerodynamic studies have investigated the tonal South Kyungsang dialect. The comparison of the aerodynamic properties between the Seoul and South Kyungsang dialects not only provides new data with regard to a tonal dialect, but also increases our understanding of the relation between tone and segment in articulatory terms.

In particular, the present study aims to address the following questions. First, does the presence of lexical pitch in South Kyungsang Korean show up in the aerodynamic measures? As noted in Lieberman \& Blumstein (1988: 107), the primary determinant of f0 variation is the subglottal air pressure; therefore, if the presence of lexical pitch in South Kyungsang Korean is reflected in acoustic properties as reported in Kenstowicz \& Park (2006), we reasonably expect a reflection of tone in aerodynamic properties, particularly oral air pressure. Second, we investigate whether and how the difference in tonal system between the two Korean dialects is reflected in the aerodynamic measures for the three voiceless stops. Finally, considering the acoustic and aerodynamic findings, a phonological representation of stops is suggested for Seoul and South Kyungsang Korean. 
Table 1 Stimuli recorded for the acoustic study.

\begin{tabular}{|c|c|c|c|c|c|}
\hline \multirow{4}{*}{$\begin{array}{l}\text { Fortis } \\
\text { Lenis } \\
\text { Aspirated }\end{array}$} & \multirow{4}{*}{$\begin{array}{l}\mathrm{p}^{\prime} \\
\mathrm{p} \\
\mathrm{p}^{\mathrm{h}}\end{array}$} & \multicolumn{2}{|c|}{ HH } & \multicolumn{2}{|c|}{ LH } \\
\hline & & p'an-i & 'bread' & p'alum & 'being fast' \\
\hline & & pal-i & 'foot' & pantal & 'a half-moon' \\
\hline & & $\mathrm{p}^{\mathrm{h}}$ an-i & 'board' & $\mathrm{p}^{\mathrm{h}} \mathrm{atfu}$ & (name of city) \\
\hline Fortis & $\mathrm{t}^{\prime}$ & t'al-i & 'daughter' & t'alum & 'following' \\
\hline Lenis & $\mathrm{t}$ & tal-i & 'moon' & tali & 'leg' \\
\hline Aspirated & $\mathrm{t}^{\mathrm{h}}$ & $\mathrm{t}^{\mathrm{h}} \Lambda \mathrm{l}-\mathrm{i}$ & "hair'a & $\mathrm{t}^{\mathrm{h}} \mathrm{al}-\mathrm{i}$ & 'mask' \\
\hline Fortis & $\mathrm{k}^{\prime}$ & k'aki & 'to peel' & k'apul & 'naughtiness' \\
\hline Lenis & $\mathrm{k}$ & katfi & 'branch' & katfi & 'eggplant' \\
\hline Aspirated & $\mathrm{k}^{\mathrm{h}}$ & $\mathrm{k}^{\mathrm{h}} \mathrm{al}-\mathrm{i}$ & 'knife' & $\mathrm{k}^{\mathrm{h}}$ oil & 'coil' \\
\hline
\end{tabular}

${ }^{a}$ The word / $\mathrm{t}^{\mathrm{h}} \mathrm{\Lambda l}-\mathrm{i} /$ 'hair-NOM' with a HL pitch pattern was used since we were unable to find a suitable HH word with an initial alveolar aspirated stop.

\section{Experiment 1: Acoustic study}

\subsection{Participants}

Sixteen native speakers of Korean participated in both the acoustic and aerodynamic studies. The data were collected from Seoul and South Kyungsang (near Pusan city) dialectal groups. Each group had eight male speakers. The age in the Seoul dialectal group ranged from 21 to 32 years old (mean $=27.6$ ). The age in the South Kyungsang dialect group ranged from 24 to 48 years old (mean $=34.9$ ). All of the speakers in each dialectal group had lived and had been educated in the target dialect region with parents who spoke the same target dialect for at least 20 years. The speakers were graduate or undergraduate students at the University of Kansas. None of the speakers in either dialect group reported any speech or hearing disorders, and all of the speakers were literate in Korean.

\subsection{Speech materials}

Disyllabic stimuli consisting of all nine stops (3 laryngeal types $\times 3$ places of articulation) in initial position and differing in initial tone (HH vs. $\mathrm{LH}$ ) were recorded in both dialects. Since the present study focuses on the acoustic cues of the three-way laryngeal distinction in the two dialects, all stimuli were categorized according to the tonal South Kyungsang dialect rather than the non-tonal Seoul dialect. For the measurement and analyses, therefore, it is assumed that the same stimuli in both dialect groups have the same pitch accent condition. For example, the stimulus /tali/ 'leg', which is LH in South Kyungsang, is also treated as LH for the non-tonal Seoul dialect. Disyllabic words were drawn from each of the two contrasting $\mathrm{HH}$ and LH pitch patterns with systematically varying initial consonants. In addition, if there was no disyllabic word with the appropriate pitch pattern, monosyllabic words followed by the nominative case marker /-i/ with HH and LH pitch patterns were used. Most of the stimuli contained the vowel /a/ in the first syllable, and target consonants were placed in initial position. Overall, a total of 576 tokens were obtained (18 target words $\times 2$ repetitions $\times$ 16 speakers) for the acoustic study (see Table 1). Most of the stimuli were adopted from Kenstowicz \& Park's (2006) study.

\subsection{Procedure}

All speakers were recorded in the anechoic chamber at the University of Kansas, using a cardioid microphone (Electrovoice-RE 20) and a digital recorder (Marantz PMD 671). Each speaker in both dialectal groups produced the target words written in standard Korean 
orthography in isolation. While subjects were instructed to produce only the target words in isolation, the words or phrases triggering the context were written next to the target words to help speakers produce the word more naturally and distinguish it from homonyms. For example, the target word for 'eggplant', which is /katfi/ in Korean, was written with the context of 'I eat __.'. The target word for 'branch', which is also /katfi/ in Korean, was written with the context of 'Look at the bird on the __.'. All of the triggering contexts were declarative sentences, and each subject was instructed to produce the target stimuli as if in a declarative utterance. The reading of the stimulus list was practiced by each of the subjects before the actual recording. The stimuli were recorded at a sampling rate of $22050 \mathrm{~Hz}$ and analyzed using the software package Praat (Boersma \& Weenink 2007).

\subsection{Measurements}

Voice onset time (VOT), fundamental frequency (f0) and the amplitude difference between the first and the second harmonic $(\mathrm{H} 1-\mathrm{H} 2)$ were measured using Praat. VOT was measured from the point of stop burst release to the onset of voicing as seen in both waveform and spectrogram. The onset of the first full period was determined as the onset of voicing as indicated in the waveform, additionally checked with the onset of the first formant in the spectrogram. f0 was calculated by hand based on measurements of the period of the vowel across the second and third pulses of the vowel following the target stop. The amplitude values for obtaining $\mathrm{H} 1-\mathrm{H} 2$ were taken using FFT spectra with a $25 \mathrm{~ms}$ window placed at the onset of the second full glottal pulse of the vowel. The spectral resolution was $21.53 \mathrm{~Hz}$.

\subsection{Results}

Measurements were averaged across all three places of articulation and the two repetitions for each speaker. All the data were evaluated based on repeated measures General Linear Model (GLM) Analyses of Variance (ANOVAs) with the following factors: Laryngeal Distinction (fortis, lenis, aspirated), Pitch Pattern (HH vs. $\mathrm{LH}$ ) as within-subjects factors and Dialect (Seoul vs. South Kyungsang) as a between-subjects factor. The three acoustic properties VOT, H1-H2 and f0 were all entered as dependent variables. Three-way repeated measures ANOVAs were conducted for each of the three dependent variables in the acoustic study and Bonferroni post hoc comparisons were conducted $(\alpha=.05)$ when significant main effects were obtained. After conducting Mauchly's test of sphericity, Huyhn-Feldt corrected degrees of freedom were used to report $F$-ratio and $p$-value for those cases where the sphericity assumption was violated.

Before considering Pitch Pattern as a factor in the statistical evaluation, this study first compared the f0 differences between HH and LH stimuli in Seoul and South Kyungsang Korean, pooled across three stop categories. This was done to verify that there is an absolute pitch difference between the initial High and Low pitch syllables in the South Kyungsang dialect compared to Seoul, and to justify the use of Pitch Pattern as a factor. A one-way ANOVA with the f0 difference between $\mathrm{HH}$ and LH stimuli as dependent variable and Dialect as independent variable showed a significant effect of Dialect $(F(1,14)=26.668, p<.001)$. The f0 difference at the onset of the initial syllable between $\mathrm{HH}$ and $\mathrm{LH}$ stimuli was $1 \mathrm{~Hz}$ for the Seoul dialect and $13 \mathrm{~Hz}$ for the South Kyungsang dialect. The Dialect effect indicates that Seoul does not have a pitch difference between the initial High (HH) and Low (LH) pitch syllables, while South Kyungsang does indeed have a pitch difference between those two pitch patterns, showing higher fo for HH than LH. After verifying the pitch distinction for the contrastive pitch patterns in South Kyungsang Korean, all subsequent statistical analyses considered Pitch Pattern as a factor. 
Table 2 Average VOT duration (ms) in the Seoul and South Kyungsang dialects as a function of Laryngeal Distinction and Pitch Pattern (standard deviation in parentheses)

\begin{tabular}{llllr}
\hline & & Fortis & Lenis & \multicolumn{1}{c}{ Aspirated } \\
\hline Seoul & HH & $18(3.58)$ & $64(21.34)$ & $80(17.57)$ \\
& LH & $17(2.92)$ & $66(15.56)$ & $81(14.65)$ \\
South Kyungsang & HH & $18(6.21)$ & $38(5.80)$ & $103(17.11)$ \\
& LH & $18(3.52)$ & $39(5.17)$ & $105(19.81)$ \\
Total mean & & $18(3.95)$ & $52(19.02)$ & $92(20.53)$ \\
\hline
\end{tabular}

\subsubsection{VOT}

Since Mauchly's test of sphericity reported no violation of sphericity for VOT, the statistical evaluation of Pitch Pattern and Laryngeal Distinction is reported without correction. A three-way repeated measures ANOVA (Laryngeal Distinction by Pitch Pattern by Dialect) reported a significant main effect of Laryngeal Distinction $(F(2,28)=178.435, p<.001)$ and a significant interaction between Laryngeal Distinction and Dialect $(F(2,28)=21.066$, $p<.001)$. However, there was no significant main effect of Pitch Pattern or Dialect, and there were no interactions between Laryngeal Distinction and Pitch Pattern, Pitch Pattern and Dialect or Laryngeal Distinction and Pitch Pattern and Dialect. Bonferroni post hoc comparisons showed that the VOT of each Laryngeal Distinction is significantly different from the others at $p<.01$ for each comparison. The comparisons showed that VOT is shortest for the fortis stop, intermediate for the lenis stop, and longest for the aspirated stop. A summary of the results is shown in Table 2.

VOT variation does not show a parallel pattern between the two dialects: the VOT for the lenis stop is significantly longer in Seoul than in South Kyungsang, while the VOT for the aspirated stop is longer in South Kyungsang than in Seoul. The signficant Laryngeal Distinction by Dialect interaction indicates that the two dialects of Korean use VOT differently to categorize the three-way stop contrast.

\subsubsection{H1-H2}

Since Mauchly's test of sphericity reported no violation of sphericity for H1-H2, the statistical evaluation of Pitch Pattern and Laryngeal Distinction is reported without correction. A threeway repeated measures ANOVA (Laryngeal Distinction by Pitch Pattern by Dialect) showed a significant main effect of Laryngeal Distinction $(F(2,28)=31.018, p<.001)$ and of Pitch Pattern $(F(1,14)=41.091, p<.001)$, as well as a significant interaction between Laryngeal Distinction and Pitch Pattern $(F(2,28)=12.816, p<.001)$. In addition, there was a trend towards significance for the interaction between Laryngeal Distinction and Dialect $(F(2,28)=3.015, p=.065)$. However, no main effect of Dialect, and no two-way interactions of Laryngeal Distinction by Dialect, Pitch Pattern by Dialect or three-way interaction of Laryngeal Distinction by Pitch Pattern by Dialect were found. Regarding the main effect of Laryngeal Distinction, Bonferroni post hoc comparisons showed that the $\mathrm{H} 1-\mathrm{H} 2$ of each Laryngeal Distinction is significantly different from the others at $p<.01$ for each comparison, reporting the smallest (negative) value for the fortis stop, intermediate value for the lenis stop and greatest value for the aspirated stop. This indicates that the vowel after the fortis stop is more creaky and the vowel after the aspirated stop is more breathy. As for the effect of Pitch Pattern, Bonferroni post hoc comparison indicated that the $\mathrm{H} 1-\mathrm{H} 2$ value obtained from the $\mathrm{HH}$ pattern was greater than that from the LH pattern at $p<.01$. A summary of the results is shown in Table 3.

Since the interaction between Laryngeal Distinction and Pitch Pattern was significant, the effect of Laryngeal Distinction was tested separately for each Pitch Pattern. While Bonferroni post hoc tests indicated an $\mathrm{H} 1-\mathrm{H} 2$ pattern of Fortis $<$ Lenis $<$ Aspirated $(p<.05)$ for the HH pattern, there was no statistical difference between Lenis and Aspirated $(p=.434)$ in the LH 
Table 3 Average values of H1-H2 (dB) in the Seoul and South Kyungsang dialects as a function of Laryngeal Distinction and Pitch Pattern (standard deviation in parentheses).

\begin{tabular}{lllll}
\hline & & Fortis & Lenis & Aspirated \\
\hline Seoul & HH & $-0.15(3.14)$ & $0.69(3.29)$ & $6.73(4.26)$ \\
& LH & $-1.07(2.99)$ & $0.51(3.83)$ & $3.02(3.56)$ \\
South Kyungsang & HH & $-2.72(3.11)$ & $1.43(4.37)$ & $4.06(4.03)$ \\
& LH & $-4.33(3.42)$ & $0.32(5.74)$ & $0.47(4.19)$ \\
Total mean & & $-2.07(3.78)$ & $0.74(4.16)$ & $3.57(4.94)$ \\
\hline
\end{tabular}

Table 4 Average value of $\mathrm{fO}(\mathrm{Hz})$ in the Seoul and South Kyungsang dialects as a function of Laryngeal Distinction and Pitch Pattern (standard deviation in parentheses).

\begin{tabular}{|c|c|c|c|c|}
\hline & & Fortis & Lenis & Aspirated \\
\hline \multirow[t]{2}{*}{ Seoul } & $H H$ & 143 (12.02) & $116(8.42)$ & 158 (16.11) \\
\hline & LH & 140 (11.94) & $117(8.6)$ & 157 (16.65) \\
\hline \multirow[t]{2}{*}{ South Kyungsang } & HH & $136(26.92)$ & 122 (18.22) & 156 (19.69) \\
\hline & LH & 124 (24.92) & $111(15.43)$ & $140(18.29)$ \\
\hline Total mean & & 136 (18.92) & $117(12.90)$ & $152(18.18)$ \\
\hline
\end{tabular}

pattern, indicating a pattern of Fortis $<$ Lenis $=$ Aspirated. Notably, there was no interaction between Pitch Pattern and Dialect, indicating that $\mathrm{H} 1-\mathrm{H} 2$ values for $\mathrm{HH}$ and $\mathrm{LH}$ are similar between Seoul and Kyungsang Korean. In terms of dialectal variation in categorizing the three stops, the lack of an interaction between Laryngeal Distinction and Dialect suggests that the two dialects of Korean use $\mathrm{H} 1-\mathrm{H} 2$ similarly to signal the three-way distinction among voiceless stops.

\section{5 .3 fo}

Since Mauchly's test of sphericity reported no violation of sphericity for f0, the statistical evaluation of Pitch Pattern and Laryngeal Distinction is reported without correction. A threeway repeated measures ANOVA (Laryngeal Distinction by Pitch Pattern by Dialect) showed a significant main effect of Laryngeal Distinction $(F(1.814,25.401)=108.958, p<.001)$ and of Pitch Pattern $(F(1,14)=49.627, p<.001)$. In addition to the main effects, two-way interaction effects of Laryngeal Distinction by Dialect $(F(1.814,25.401)=4.579, p=.023)$ and Pitch Pattern by Dialect $(F(1,14)=35.147, p<.001)$ and a three-way interaction of Laryngeal Distinction by Pitch Pattern by Dialect $(F(2,28)=5.914, p=.007)$ were obtained. However, no main effect of Dialect, and no interaction between Laryngeal Distinction and Pitch Pattern were found. As for the main effect of Laryngeal Distinction, Bonferroni post hoc comparisons showed that the f0 of each Laryngeal Distinction is significantly different from the others at $p<.01$ for each comparison. The comparisons showed that f0 is lowest for the lenis stop, intermediate for the fortis stop, and greatest for the aspirated stop. Regarding the effect of Pitch Pattern, post hoc comparisons showed that $\mathrm{f0}$ for the HH pattern was higher than that for the LH pattern at $p<.01$. Table 4 shows the comparison between the two dialects.

Regarding the reported interaction effects, the interaction of Pitch Pattern by Dialect indicates that the two dialects of Korean use f0 in different ways to mark Pitch Pattern. Table 4 shows that while South Kyungsang Korean has distinctive f0 values depending on $\mathrm{HH}$ and LH patterns across all three stops, Seoul Korean does not. Importantly, the significant interaction between Laryngeal Distinction and Dialect indicates that Seoul and South Kyungsang Korean use f0 differently to distinguish the three-way stop contrast. Table 5 presents the f0 differences 
Table $5 \mathrm{fO}(\mathrm{Hz})$ differences among Laryngeal Distinctions in the Seoul and South Kyungsang dialects across Pitch Pattern (standard deviation in parentheses).

\begin{tabular}{lll}
\hline & Seoul & South Kyungsang \\
\hline Fortis - Lenis & $25(7.88)$ & $12(9.02)$ \\
Aspirated - Fortis & $15(8.36)$ & $16(6.41)$ \\
Aspirated - Lenis & $40(15.50)$ & $29(5.22)$ \\
\hline
\end{tabular}

among all three stops separately for the two dialects and shows that the Seoul dialect generally had a larger f0 difference compared to the South Kyungsang dialect.

Finally, the three-way interaction suggests that the difference in Pitch Pattern between the dialects is responsible for the different use of f0.

\subsection{Summary and discussion}

\subsubsection{Summary of results}

The present study not only replicated previous results, but also reported several new findings regarding dialectal variation. First, South Kyungsang Korean was shown to indeed have pitch differences between $\mathrm{HH}$ and $\mathrm{LH}$ patterns in the initial syllables. This allowed us to explore if the presence of the pitch accent contrast in South Kyungsang Korean has an influence on f0 as an acoustic cue for the Korean stop distinction. Accordingly, we examined how the difference in using f0 between the two dialects affected other cues such as VOT and H1-H2. Significant main effects of Laryngeal Distinction on VOT, H1-H2 and f0 were obtained. In addition, there were significant interactions between Laryngeal Distinction and Dialect for VOT and f0, which suggest that these acoustic cues to the three-way laryngeal distinction are used differently in the two dialects.

VOT is significantly different among the three-way laryngeal distinction: VOT is shortest for the fortis, intermediate for the lenis, and greatest for the aspirated stop in both dialects, which is in line with previous findings. Regarding dialectal variation in VOT, lenis stops in the Seoul dialect have a VOT longer than in South Kyungsang; but the aspirated stops in South Kyungsang show a longer VOT than in Seoul Korean, which is the main cause of the interaction between Laryngeal Distinction and Dialect.

The amplitude difference between the first and the second harmonic $(\mathrm{H} 1-\mathrm{H} 2)$ was also significant across all three stops: $\mathrm{H} 1-\mathrm{H} 2$ was smallest for the fortis stop, intermediate for the lenis stop and largest for the aspirated stop. However, follow-up comparisons after noting the interaction between Laryngeal Distinction and Pitch Pattern indicated that while the HH pitch pattern showed an H1-H2 pattern of Fortis < Lenis < Aspirated, the LH pattern showed no difference between the lenis and aspirated stops. There were no interactions involving Dialect, indicating no dialectal variation in the use of the H1-H2 cue. Notably, given the main effect of Pitch Pattern, the lack of an interaction between Pitch Pattern and Dialect implies that the Pitch Pattern affects $\mathrm{H} 1-\mathrm{H} 2$ similarly in both dialects.

With regard to f0, there were significant main effects of Laryngeal Distinction and Pitch Pattern. Bonferroni tests revealed that $\mathrm{f0}$ was significantly different among the three Korean stops, with fo being highest for the aspirated stop, intermediate for the fortis stop, and lowest for the lenis stop, and this is also consistent with previous reports. Regarding dialectal variation in $\mathrm{f0}$, the $\mathrm{f0}$ difference between the fortis and lenis stops and between the lenis and aspirated stops was greater in Seoul Korean than in South Kyungsang, as indicated by the interaction between Laryngeal Distinction and Dialect. Importantly, the three-way interaction 
of Laryngeal Distinction by Pitch Pattern by Dialect implies that the presence of lexical pitch accent in South Kyungsang Korean is the cause of the dialectal variation.

\subsubsection{Discussion}

The present results indicate that although the two dialects share the same lexical items and three-way laryngeal distinction, the different tonal systems between the dialects have an influence on the acoustic cues. We first verified the presence of a pitch accent contrast (HH vs. LH) in South Kyungsang only. Voice quality measures (e.g. f0, H1-H2) have been proposed as primary acoustic cues for Korean stops in previous studies (e.g. Han \& Weitzman 1970, C.-W. Kim 1970, Cho 1996, Cho et al. 2002) along with consonant durational properties. If the function of $\mathrm{f0}$ is different for the three stop categories due to the different tonal systems between the two dialects, we might expect the contribution of other acoustic cues to also differ depending on the cue weighting of $\mathrm{f} 0$ in each dialect.

Fundamental frequency patterns in accordance with previous reports are: lowest for the lenis, intermediate for the fortis and greatest for the aspirated stop, suggesting that the laryngeal specification of the consonant correlates with the f0 value of the following vowel. Consequently, the current study supports the findings by Cho et al. (2002) and Kang \& Guion (2008) which reported f0 values from low to high in the order of lenis, fortis and aspirated stops in Korean. However, the interaction between Laryngeal Distinction and Dialect indicates that the two dialects use f0 in different ways and suggests that $\mathrm{f0}$ cue weights are different between Seoul and South Kyungsang Korean. In fact, the f0 differences among the three stops were greater for Seoul than for South Kyungsang Korean in most cases. In addition, the three-way interaction among factors (i.e. Laryngeal Distinction, Pitch Pattern and Dialect) on f0 suggested a relation between lexical pitch accent and dialectal variation. For further analysis, the current study statistically evaluates f0 differences for the three stops across HH and LH patterns, using separate paired sample $t$-tests for Seoul and Kyungsang Korean. Paired sample $t$-tests reported non-significant f0 differences between the HH lenis stop and the LH fortis stop $(p=.822)$, and between the HH fortis and LH aspirated stop within the South Kyungsang data $(p=.728)$, while all the comparisons were significant in the Seoul data. This suggests that unlike the Seoul dialect, in which f0 is significantly different among the three Korean stops, f0 is not a reliable acoustic cue for South Kyungsang speakers to distinguish the three-way Korean stop contrast.

In an attempt to provide more concrete evidence about the contribution of $\mathrm{f} 0$ as a single predictor, multiple discriminant function analysis (with three groups: fortis, lenis, aspirated) was conducted. For the Seoul dialect, f0 as a single predictor classified the three stop types with $77 \%$ accuracy, but for South Kyungsang, accuracy was only $54 \%$. This confirms that f0 is a better predictor for categorizing the three-way stop contrast for non-tonal Seoul than for tonal Kyungsang. Consequently, we conclude that the use of $\mathrm{f0}$ for tonal distinctions makes f0 a less reliable acoustic cue for the stop contrast in Kyungsang than in Seoul.

Since f0 turns out to be a less reliable acoustic cue for South Kyungsang speakers, it may be expected that the role of other acoustic cues such as VOT and H1-H2 is greater in South Kyungsang than in Seoul Korean to compensate for the reduced role of fo. We can reasonably speculate that VOT is a compensating factor for f0 in South Kyungsang Korean based on the interaction between Laryngeal Distinction and Dialect for VOT, but not for H1-H2. The experimental results showed that VOT is shortest for the fortis, intermediate for the lenis and longest for the aspirated stop. However, despite the main effect of Laryngeal Distinction across dialects, Figure 2 shows that the VOT distribution is different in the two dialects.

Figure 2 shows that the interquartile ranges overlap significantly between the lenis and aspirated stop for Seoul, while the VOT distribution for South Kyungsang is well separated. Discriminant analyses were performed to evaluate the role of VOT as a single predictor in both dialects. For the Seoul dialect, VOT as a single predictor only yields a $71.5 \%$ accurate classification rate, but for South Kyungsang, this is $83 \%$. The different classification accuracy is also apparent when we look at the mean differences in VOT between the lenis and aspirated 
Table 6 Comparison of VOT values (ms) reported by Cho et al. 2002, Kang \& Guion 2008 and the current study. The values from Cho et al. 2002 and Kang \& Guion 2008 are estimated from graphs.

\begin{tabular}{lllll}
\hline & & Fortis & Lenis & Aspirated \\
\hline Cho et al. 2002 & Seoul & 20 & 72 & 120 \\
& Cheju & 20 & 47 & 105 \\
Kang \& Guion 2008 (clear speech condition) & Young & 10 & 63 & 75 \\
& Old & 10 & 60 & 90 \\
Current study & Seoul & 17 & 65 & 80 \\
& Kyungsang & 18 & 38 & 104 \\
\hline
\end{tabular}
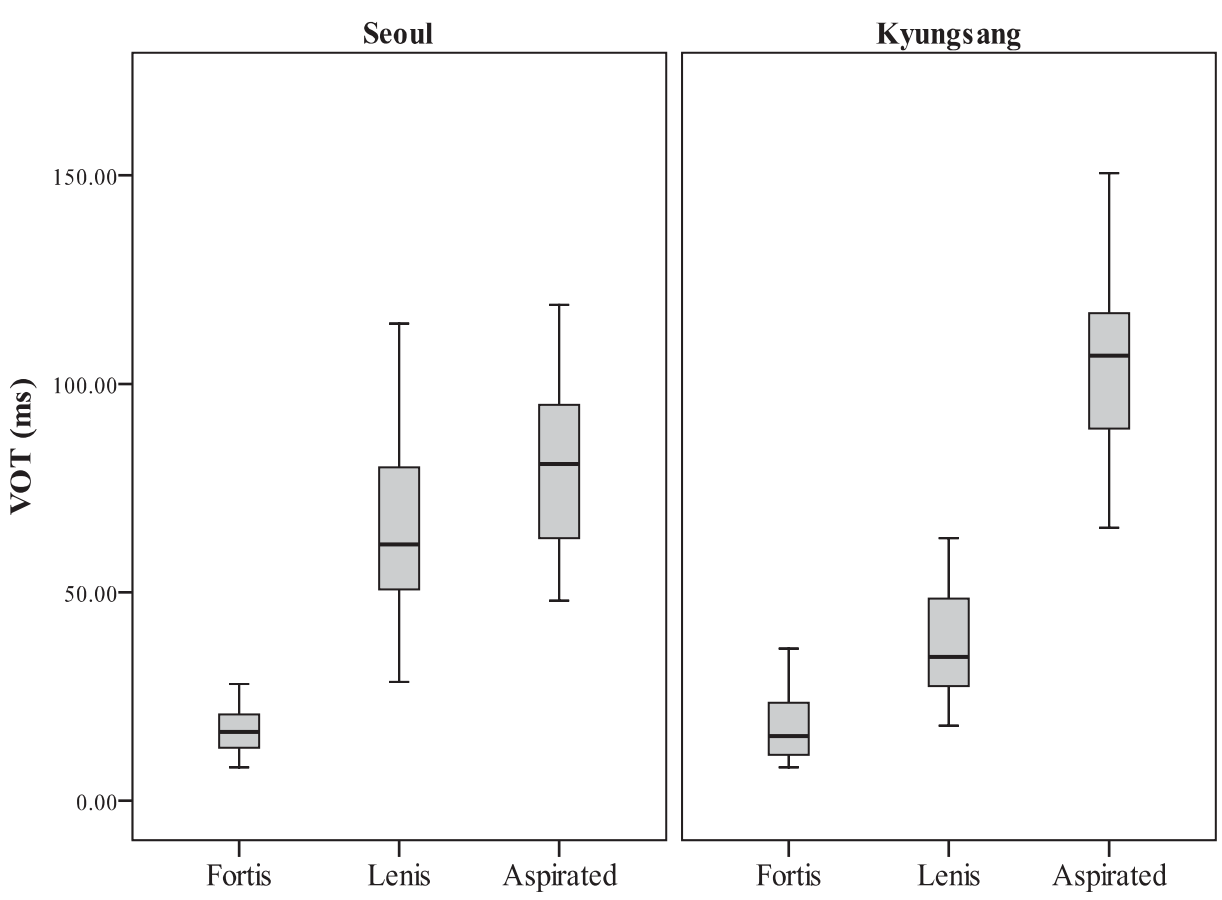

Figure 2 VOT distribution for Seoul and South Kyungsang Korean. The horizontal line in each box represents the median value of the data, and the ends of the vertical lines indicate the minimum and maximum data values.

stop; the mean VOT difference between the lenis and aspirated stop is $66 \mathrm{~ms}$ for South Kyungsang, but only $15 \mathrm{~ms}$ for Seoul Korean.

Silva (2006) has observed that VOT differences between the lenis and aspirated stop have decreased over the past 50 years, and suggested age variation as an explanation for the VOT pattern in Seoul Korean. The current results support Silva's (2006) argument for a historical transition, confirming that younger Seoul speakers are more likely to minimize the VOT difference between the lenis and aspirated stop. This notion becomes clearer when compared with the Cho et al. (2002) and Kang \& Guion (2008) studies. Table 6 shows previously reported VOT values including Cho et al.'s (2002) measurements for Seoul and Cheju speakers, and Kang \& Guion's (2008) measurements for young and old Seoul speakers as well as the VOT values obtained in the current study.

While the present VOT values for the fortis and lenis stop for the Seoul dialect are comparable to those in Cho et al. (2002), the average value for the aspirated stop is lower. The 
notion that older speakers are more likely to maintain a clear distinction between the lenis and aspirated stop can be evaluated by comparing the VOT values and speakers' ages between Cho et al.'s (2002) study and the current study: the Seoul speakers in Cho et al. (2002) were in their late 50 s and early 60 s while the mean age of Seoul speakers in the present study is 27.6 years.

The study by Kang \& Guion (2008) also supports a generational change in VOT. Kang \& Guion (2008) reported VOT values among the three Korean voiceless stops by comparing clear speech to conversational speech and citation-form speech conditions. Kang \& Guion (2008) reported greater VOT differences between the lenis and aspirated stops for the old group (30 $\mathrm{ms})$ than for the young group (12 ms) in the clear speech condition; in the conversational speech condition, the VOT difference between the lenis and aspirated stops was $18 \mathrm{~ms}$ for the old group, but there was no difference $(0 \mathrm{~ms})$ for the young group.

Overall, the reports of the discriminant analysis and the well-separated VOT values between the lenis and aspirated stop in South Kyungsang suggest that VOT is a stronger predictor for categorizing the three-way stop distinction for South Kyungsang, which does not primarily rely on $\mathrm{f} 0$ to distinguish the three stops due to the presence of tonal contrasts. In other words, Kyungsang speakers primarily use VOT to distinguish the three-way laryngeal distinction, while Seoul speakers primarily use f0 or a combination of $\mathrm{fO}$ and VOT. In addition, dialectal differences in VOT to mark the three-way distinction support the notion of a diachronic transition whereby VOT differences between the lenis and aspirated stops in Seoul Korean have been decreasing over the past 50 years.

The current study also investigated the phonation type of Korean stops by measuring $\mathrm{H} 1-\mathrm{H} 2$ in the following vowel. $\mathrm{H} 1-\mathrm{H} 2$ in the following vowel is significantly different across all three stops, patterning Fortis $<$ Lenis $<$ Aspirated. This indicates that the vowel following the aspirated stop is breathier than the vowel following any other stop category. In contrast, the vowel after the fortis stop has creakier voice than the others (Han \& Weitzman 1970, Blankenship 2002, Cho et al. 2002, Kang \& Guion 2008). Regarding dialectal differences in the use of $\mathrm{H} 1-\mathrm{H} 2$ to distinguish the three stops, there was an interaction trend $(p=.065)$ between Laryngeal Distinction and Dialect. This indicates that Seoul and South Kyungsang Korean tend to use H1-H2 differently. Post hoc comparison showed that H1-H2 cannot distinguish the fortis stop from the lenis stop in Seoul Korean, but it can distinguish the lenis from the aspirated stop in South Kyungsang Korean. Discriminant analyses were performed to assess if the H1-H2 cue is more reliable for South Kyungsang than for Seoul Korean, and thereby to determine if $\mathrm{H} 1-\mathrm{H} 2$ compensates for the weakened f0 for South Kyungsang along with VOT. Discriminant analysis reported that $\mathrm{H} 1-\mathrm{H} 2$ alone classifies the three categories of Korean stops with $47 \%$ and 52\% accuracy for the Seoul and for the South Kyungsang dialect, respectively. This indicates that although $\mathrm{H} 1-\mathrm{H} 2$ is a stronger cue for South Kyungsang than for Seoul Korean, it does not compensate for f0 in South Kyungsang Korean as much as VOT does (Seoul 72\%, South Kyungsang 83\%). Importantly, this contradicts Kenstowicz \& Park (2006), who suggested H1-H2 as a measure to compensate for f0 in Kyungsang Korean.

Given the main effect of Pitch Pattern, the lack of an interaction between Pitch Pattern and Dialect would seem to require discussion. This indicates that the effect of Pitch Pattern on H1-H2 is similar for both Seoul and Kyungsang Korean. In other words, an effect of Pitch Pattern was found not only for tonal Kyungsang Korean, but also for non-tonal Seoul Korean. For further analysis, the current study tested whether the effect of Pitch Pattern in Seoul Korean occurs for all three laryngeal types, or is limited to a particular type. A paired sample $t$-test showed that $\mathrm{H} 1-\mathrm{H} 2$ between the $\mathrm{HH}$ and $\mathrm{LH}$ pattern was significantly different only for the aspirated stop at $p<.05$ (mean in $\mathrm{HH}=6.73 \mathrm{~dB}$, mean in $\mathrm{LH}=3.02 \mathrm{~dB}$ ), while $\mathrm{H} 1-\mathrm{H} 2$ was not statistically different between $\mathrm{HH}$ and $\mathrm{LH}$ pitch patterns for the fortis and lenis stops.

The unexpected Pitch Pattern effect for the aspirated stop in Seoul Korean may be due to vowel quality differences in the speech materials in the present study. As noted in previous research on voice quality (e.g. Wayland \& Jongman 2003, Iseli \& Alwan 2004, Keating \& Esposito 2007), H1 is highly influenced by the frequency of the first formant, and the boosting 
Table 7 Comparison of H1-H2 patterns in previous acoustic studies. (The statistical evaluation in Park (2002) was done for each of the three Seoul speakers; while two speakers showed Fortis $<$ Lenis $=$ Aspirated, one speaker showed Fortis $<$ Lenis $<$ Aspirated patterns.)

\begin{tabular}{lll}
\hline Study & Dialect & H1-H2 Pattern \\
\hline Cho et al. 2002 & Seoul & Fortis $<$ Aspirated $<$ Lenis \\
& Cheju & Fortis $<$ Aspirated $<$ Lenis \\
Kenstowicz \& Park 2006 & Kyungsang & Fortis $<$ Aspirated $<$ Lenis \\
Ahn 1999 & Seoul & Fortis $<$ Lenis $<$ Aspirated \\
Park 2002 & Seoul & Fortis $<$ Lenis $\leq$ Aspirated \\
Kang \& Guion 2008 & Seoul & Fortis $<$ Lenis $<$ Aspirated \\
Current study & Seoul/Kyungsang & Fortis $<$ Lenis $<$ Aspirated \\
\hline
\end{tabular}

effect of $\mathrm{F} 1$ on the amplitudes of $\mathrm{H} 1$ and $\mathrm{H} 2$ among high vowels typically requires researchers to correct the H1-H2 value using normalization algorithms (e.g. Hanson 1995, Iseli \& Alwan 2004) or to use only low vowels. In the present study, the stimulus for the aspirated stop in LH was $/ \mathrm{k}^{\mathrm{h}} \mathrm{oil} /$ 'coil' and the corresponding word in HH was $/ \mathrm{k}^{\mathrm{h}} \mathrm{al}-\mathrm{i} /$ ' $k$ nife-NOM'. Thus, the difference in first formant frequency between the vowels /o/ and /a/ in the current study could have affected the amplitude of the lower harmonics. This would result in a large $\mathrm{H} 1-\mathrm{H} 2$ difference between $\mathrm{HH} / \mathrm{k}^{\mathrm{h}}$ al-i/ and $\mathrm{LH} / \mathrm{k}^{\mathrm{h}}$ oil/ stimuli, and, consequently, it would appear as if Seoul Korean had a Pitch Pattern effect in the aspirated stop category.

To see if the difference in vowel quality (i.e. formant frequency) indeed affected H1H2, a three-way ANOVA (Laryngeal Distinction by Pitch Pattern by Dialect) was conducted excluding the velar aspirated stop in HH and LH conditions (i.e. $/ \mathrm{k}^{\mathrm{h}} \mathrm{al}-\mathrm{i} / \mathrm{(HH}$ ) 'knife-NOM' and $/ \mathrm{k}^{\mathrm{h}} \mathrm{oil} /(\mathrm{LH})$ 'coil'). Before the exclusion of the aspirated velar stops, there was no significant interaction between Pitch Pattern and Dialect $(F(1,14)=0.747, p=.402)$. However, exclusion of the aspirated velar stops resulted in a strong trend for the interaction between Pitch Pattern and Dialect $(F(1,14)=3.622, p=.078)$. This trend indicates a dialectal difference in Pitch Pattern, suggesting that the pitch difference between $\mathrm{HH}$ and $\mathrm{LH}$ affected $\mathrm{H} 1-\mathrm{H} 2$ more greatly for South Kyungsang than for Seoul Korean. Importantly, the interaction trend without the aspirated velar stops indicates that the unexpected Pitch Pattern effect in the Seoul data was most likely caused by a difference in vowel quality.

Several acoustic studies have examined differences in voice quality of the vowel after the Korean stop, with inconsistent results for $\mathrm{H} 1-\mathrm{H} 2$. The inconsistent $\mathrm{H} 1-\mathrm{H} 2$ reports across several studies require discussion as well. Table 7 shows the $\mathrm{H} 1-\mathrm{H} 2$ patterns documented in previous studies and in the current study.

The difference concerns the $\mathrm{H} 1-\mathrm{H} 2$ values for the lenis and the aspirated stop, while the $\mathrm{H} 1-\mathrm{H} 2$ value after the fortis stop has consistently been reported to be the smallest in all studies. Cho et al. (2002) commented that the different pattern from Ahn's (1999) study could possibly be caused by the difference in speakers' age or procedural differences. However, the role of age is questionable, since Kang \& Guion (2008) reported the same H1-H2 pattern in both younger and older speakers. Procedural differences may cause these different patterns among studies. Park (2002) also noted that the inconsistency across studies could be caused by a difference in stimuli (e.g. minimal pair or not) or stimulus context (e.g. isolation vs. carrier) among studies. Accordingly, methodological differences may explain the discrepant H1-H2 findings across studies. Importantly, regarding the inconsistent reports, particularly for the lenis and aspirated stops, we may speculate that Korean speakers use $\mathrm{H} 1-\mathrm{H} 2$ to distinguish the fortis stop from others, and rely on other acoustic cues (e.g. VOT, f0) to differentiate the lenis from the aspirated stop. However, discriminant analysis showed that $\mathrm{H} 1-\mathrm{H} 2$ classifies the three categories of Korean stops with relatively low accuracy rate compared to VOT or f0 
(47\% in Seoul, 52\% in South Kyungsang). In sum, while H1-H2 can to some extent determine the voice quality at vowel onset as a function of the preceding stop, the inconsistent pattern of H1-H2 among studies and low classification rate lead us to conclude that both Seoul and Kyungsang do not use the harmonic components as a primary cue to distinguish the Korean stops.

\section{Experiment 2: Aerodynamic study}

\subsection{Participants}

The same 16 speakers recorded in the acoustic study participated in the aerodynamic study. Since two of the Kyungsang speakers had difficulty producing the stimuli while holding a tube in their mouths for the oral air pressure measurement, data from only six of the South Kyungsang speakers were included in statistical analyses for intraoral air pressure.

\subsection{Speech materials}

The stimuli recorded in the aerodynamic study consisted of those with bilabial stops used in the acoustic study; alveolar and velar stops were not recorded because most of the subjects were not comfortable with inserting the tube through their nose to capture the pressure behind the alveolar or velar constrictions. Subjects in both dialectal groups read the bilabial stops twice for aerodynamic recording. Overall, a total of 192 tokens $(6$ target words $\times 2$ repetitions $\times$ 16 speakers) and a total of 168 tokens ( 6 target words $\times 2$ repetitions $\times 14$ speakers $)$ were obtained for the intraoral airflow and air pressure measures, respectively.

\subsection{Procedure}

Each speaker was recorded at the University of Kansas Phonetics and Psycholinguistics Laboratory (KUPPL) right after the acoustic recording. Oral airflow and pressure were recorded using the Macquirer X16 system (Scicon Company). To capture the oral airflow, speakers held a face mask against the lower part of the face, below the nose, and they also held a tube (internal diameter $2 \mathrm{~mm}$ and $6 \mathrm{~cm}$ length) between their lips to record the oral air pressure. The air pressure transducer and flow mask were calibrated with CAL 110/220 (Scicon) prior to collecting data from the speakers. The flow and pressure signals were sampled at a rate of $2 \mathrm{kHz}$ and analyzed with Macquirer (Scicon).

\subsection{Measurements}

Measurements were made of the maximum oral airflow (Uo) after the release of the stop closure, and the peak oral air pressure (Po) during the stop closure.

\subsection{Results}

As in the acoustic study, measurements were averaged across the two repetitions for each speaker. All the data were evaluated based on repeated measures General Linear Model (GLM) Analyses of Variance (ANOVAs) with the following factors: Laryngeal Distinction (fortis, lenis, aspirated), Pitch Pattern (HH vs. LH) as within-subjects factors and Dialect (Seoul vs. South Kyungsang) as a between-subjects factor. The two aerodynamic properties of intraoral airflow (Uo) and oral air pressure (Po) were entered as dependent variables. Bonferroni post hoc comparisons were conducted $(\alpha=.05)$ when significant main effects were reported. 
Table 8 Average maximum intraoral airflow $(I / s)$ in the Seoul and South Kyungsang dialects for the three-way laryngeal distinction (standard deviation in parentheses).

\begin{tabular}{lllll}
\hline & & Fortis & Lenis & Aspirated \\
\hline Seoul & HH & $1.00(0.40)$ & $2.07(0.60)$ & $2.66(0.48)$ \\
\multirow{3}{*}{ South Kyungsang } & LH & $0.97(0.46)$ & $2.00(0.55)$ & $2.85(0.50)$ \\
\multirow{2}{*}{ Mean } & HH & $0.69(0.31)$ & $1.09(0.66)$ & $1.82(0.77)$ \\
& LH & $0.60(0.25)$ & $0.95(0.51)$ & $2.10(0.73)$ \\
& & $0.82(0.38)$ & $1.53(0.76)$ & $2.36(0.71)$ \\
\hline
\end{tabular}

\subsubsection{Airflow (U0)}

Since Mauchly's test of sphericity reported no violation of sphericity for oral airflow, the statistical evaluation of Pitch Pattern and Laryngeal Distinction is reported without correction. A three-way repeated measures ANOVA (Laryngeal Distinction by Pitch Pattern by Dialect) reported significant main effects of Laryngeal Distinction $(F(2,28)=101.692, p<.001)$ and Dialect $(F(1,14)=9.856, p=.007)$, as well as a significant interaction between Laryngeal Distinction and Dialect $(F(2,28)=5.077, p=.013)$ and between Laryngeal Distinction and Pitch Pattern $(F(2,28)=9.349, p=.001)$. However, there was neither a significant main effect of Pitch Pattern nor interaction effects of Pitch Pattern by Dialect or Laryngeal Distinction by Pitch Pattern by Dialect. Bonferroni post hoc comparisons showed that the airflow rate of each Laryngeal Distinction is significantly different from the others at $p<.01$ for each comparison. The maximum intraoral airflow rate was lowest for the fortis stop, intermediate for the lenis stop, and greatest for the aspirated stop. As for the main effect of Dialect, the airflow rate was greater in Seoul Korean than in Kyungsang. A summary of the results is presented in Table 8.

The interaction effect of Laryngeal Distinction by Pitch Pattern was caused by the aspirated stop; while the airflow rate was greater in the $\mathrm{HH}$ pitch pattern for the fortis and lenis stops, the aspirated stop showed greater values in the LH pattern. Regarding the dialectal variation in airflow rates, the interaction between Laryngeal Distinction and Dialect seems to come from the lenis stop for which the airflow difference between the two dialects is greater than for any other stop category.

\subsubsection{Air pressure ( $\mathrm{Po})$}

Since the outcome of Mauchly's test was significant $(p<.05)$ for oral air pressure, indicating a violation of the assumption of sphericity, Huynh-Feldt corrected values are reported here. A three-way repeated measures ANOVA (Laryngeal Distinction by Pitch Pattern by Dialect) showed a main effect of Laryngeal Distinction $(F(1.543,18.518)=5.129, p=.023)$ and Pitch Pattern $(F(1,12)=6.194, p=.028)$ for the intraoral air pressure. In addition, there was a significant interaction between Laryngeal Distinction and Pitch Pattern $(F(1.447,17.395)=$ $6.032, p=.016$ ). However, there was no significant main effect of Dialect, and there were no significant two-way or three-way interactions including Dialect. As for the main effect of Laryngeal Distinction, Bonferroni post hoc comparisons showed that the air pressure was significantly different only between the lenis and fortis stops at $p<.01$, while other comparisons were not statistically significant (fortis-aspirated at $p=1.0$, lenis-aspirated at $p=.129)$. Statistical results indicated that the maximum intraoral air pressure is lowest for the lenis stop but comparable for the fortis and aspirated stops, and the lenis and aspirated stops. As for the Pitch Pattern effect, the oral air pressure was greater in the HH pattern than in the LH pattern. A summary of the results is shown in Table 9.

With regard to the interaction between Laryngeal Gesture and Pitch Pattern, there was no statistical difference between Lenis and Aspirated for HH $(p=.347)$, but there was a significant difference between Lenis and Aspirated for LH $(p=.044)$. 
Table 9 Average maximum intraoral air pressure $\left(\mathrm{cm} \mathrm{H}_{2} \mathrm{O}\right)$ in the Seoul and South Kyungsang dialects for the three-way laryngeal distinction (standard deviation in parentheses).

\begin{tabular}{llrll}
\hline & & \multicolumn{1}{c}{ Fortis } & \multicolumn{1}{l}{ Lenis } & Aspirated \\
\hline \multirow{2}{*}{ Seoul } & HH & $9.29(1.61)$ & $7.07(1.13)$ & $8.72(2.40)$ \\
& LH & $7.62(1.86)$ & $6.32(1.42)$ & $8.92(3.03)$ \\
South Kyungsang & HH & $10.09(1.96)$ & $8.69(1.70)$ & $8.61(2.56)$ \\
\multirow{2}{*}{ Mean } & LH & $8.81(2.72)$ & $8.05(2.08)$ & $9.34(2.53)$ \\
& & $8.88(1.81)$ & $7.41(1.69)$ & $8.89(2.44)$ \\
\hline
\end{tabular}

\subsection{Summary and discussion}

\subsubsection{Summary of results in the aerodynamic study}

To understand the articulation, in particular the subglottal and supraglottal components of Korean stop production, this study examined aerodynamic properties by measuring the intraoral airflow (Uo) and air pressure (Po). Results showed that the airflow rate was lowest for the fortis, intermediate for the lenis, and greatest for the aspirated stop. In terms of dialectal variation in airflow, Seoul speakers generally showed greater airflow rates than South Kyungsang speakers, and the difference in airflow rates between Seoul and South Kyungsang was greater in the lenis stop than the other stops, which was indicated by the interaction between Laryngeal Distinction and Dialect. As for the intraoral air pressure, there were main effects of Laryngeal Distinction and Pitch Pattern. The air pressure rate was lower in the lenis stop than in the fortis or aspirated stops, and it was greater in the $\mathrm{HH}$ pattern than in the LH pattern.

\subsubsection{Discussion}

The present study revealed different patterns between intraoral air pressure (Po) and airflow (Uo) as a function of preceding consonant types, which is consistent with previous aerodynamic studies on the Korean voiceless stops (Dart 1987, Cho et al. 2002). Observing the lowest airflow rate, but the greatest air pressure for the fortis stop, the pattern for airflow is in the order of Fortis $<$ Lenis $<$ Aspirated, and the pattern for air pressure is Lenis $<$ Fortis, Lenis $=$ Aspirated, and Fortis $=$ Aspirated.

Consistent with the previous findings, the results in the present study showed a higher oral pressure for the aspirated and the fortis stop than the lenis stop, and the airflow rate was lowest for the fortis and highest for the aspirated stop, which confirms the asymmetrical pattern of oral air pressure and airflow in the fortis stop reported in Dart (1987) and Cho et al. (2002). Dart (1987) and Cho et al. (2002) both suggested that the greater air pressure for the fortis than for the lenis stop derives from the greater subglottal pressure (Ps) for the fortis stop, but the greater glottal impedance (smaller glottal area), which can also account for the lowest airflow for the fortis stop, might lower the air pressure compared to that of the aspirated stop. Based on the post hoc comparison that revealed comparable intraoral air pressure between the fortis and aspirated stops, Cho et al. (2002) speculated that the subglottal pressure (Ps), the primary source of the oral pressure, might possibly be greater for the fortis stop than for the aspirated stop. In other words, although the fortis stop has greater subglottal pressure than the aspirated stop, the supraglottal factor (i.e. great glottal impedance) seems to block the pressure to be captured in the oral cavity, otherwise the fortis stop would be realized with greater oral pressure than the aspirated stop.

Consistent with Cho et al. (2002), we found that the air pressure (Po) between the fortis and aspirated stop is statistically comparable. In fact, while Cho et al. (2002) reported numerically greater oral air pressure values for the aspirated than for the fortis stop, we found the opposite. The finding in Cho et al. (2002) and the current study seems to support the speculation about the greater subglottal air pressure (Ps) in the fortis than in the aspirated stop with regard to the 
fact that the main source of intraoral air pressure (Po) is subglottal pressure (Ps). Although the measures of intraoral air pressure and airflow may not directly reflect the aerodynamic mechanism, the findings in the previous research and current study indicate the combined effect of subglottal and supraglottal systems in the production of contrastive segments.

Regarding the dialectal difference in the aerodynamic component, there were no two-way or three-way interactions including Dialect, except for the interaction between Laryngeal Distinction and Dialect on the oral airflow rate. This indicates that while the oral air pressure showed a similar pattern between the two dialects, oral airflow patterns differently for the three-way laryngeal distinction among voiceless stops between the two dialects of Korean. The dialectal variation in the acoustic measure of VOT seems to be reflected in the airflow measure in the present study, supporting the correlation between acoustics and articulation observed in previous research (e.g. Kagaya 1974, Dart 1987). Specifically, it is interesting to compare the interaction between Laryngeal Distinction and Dialect for oral airflow and for VOT, both of which were carried by the lenis stop. The differences in both VOT (ms) and airflow $(1 / \mathrm{s})$ were greatest in the lenis stop between the two dialects, resulting in dialectal variation for both phonetic parameters.

Kagaya (1974) has noted a linear correlation between VOT and glottal aperture. Based on her aerodynamic model, Dart (1987) also suggested that the airflow rate could be postulated by the glottal aperture generally with a positive correlation. Therefore, the interaction effects for VOT and for airflow measures seem to not only support the positive correlation between acoustics and articulation, but also to suggest that the correlation between VOT and airflow is strong enough to reflect the dialectal variation. In addition, the present study reported an effect of Pitch Pattern on intraoral air pressure, with higher pressure during the production of words with the HH pattern than with the LH pattern. This finding is in line with previous research (e.g. Shipp \& McGlone 1971, Atkinson 1978) that reported a positive correlation between subglottal pressure and f0.

In order to determine whether the acoustics and articulation are correlated, Pearson correlation coefficients were computed for the relationship between VOT and airflow, and between $\mathrm{f} 0$ and air pressure. Overall, there was a strong positive correlation between VOT and airflow $(r=.613, p<.001)$, and a moderate positive correlation between $\mathrm{f} 0$ and air pressure $(r=.398, p<.001)$. Accordingly, the present results support previous studies which suggest that acoustics and articulation are positively correlated (Shipp \& McGlone 1971, Kagaya 1974, Atkinson 1978, Dart 1987). The shared dialectal difference caused by the lenis stop for both VOT and airflow is well reflected through the strong correlation between VOT and airflow.

Dart (1987) speculated that the airflow differences during the production of Korean stops are due to differences in glottal aperture, and that the pressure differences in Korean stops can be caused by differences in subglottal pressure (Ps), vocal tract wall tension, subglottal cavity volume and stop closure duration. For example, small airflow rate could be reflected with small glottal width, and great air pressure rate could correspond to great subglottal pressure or tensed vocal tract wall tension. With respect to the articulatory states during the production of Korean stops, the cineradiographic study by C.-W. Kim (1970), and MRI study by H. Kim, Honda \& Maeda (2005) reported that the glottal opening is largest for aspirated stops, intermediate for lenis stops, and narrowest for fortis stops. C.-W. Kim (1970) suggested a direct correlation between the degree of the glottal opening at the time of release and the degree of aspiration. From the transverse MRI images of glottal width and opening, H. Kim et al. (2005) supported the results of C.-W. Kim (1970), indicating that glottal opening and glottal width vary from small to large in the order of fortis, lenis and aspirated stops.

In addition, Hirose, Lee \& Ushijima (1974) investigated the different laryngeal muscle activity by inserting electrodes during articulation of the three-way stop distinction in Seoul Korean. Hirose et al. (1974) reported that the aspirated stop is characterized by suppression of all the adductor muscles of the larynx after the release of the stop closure and a steep increase in muscle activity after the suppression. Moreover, Hirose et al. (1974) indicated a marked 
Table 10 Summary of aerodynamic and articulatory patterns for Korean stops.

\begin{tabular}{ll}
\hline Aerodynamic & Articulatory \\
\hline Airflow (Dart 1987, Cho et al. 2002) & Glottal width (C.-W. Kim 1970, H. Kim et al. 2005) \\
Fortis < Lenis < Aspirated & Fortis $<$ Lenis < Aspirated \\
Air pressure (Dart 1987, Cho et al. 2002) & Subglottal pressure (Lee \& Smith 1972) \\
Lenis < Fortis = Aspirated & Lenis $<$ Fortis \\
& Vocal fold tension (Hirose et al. 1974) \\
& Lenis $<$ Fortis = Aspirated \\
\hline
\end{tabular}

Table 11 Summary of the main acoustic and aerodynamic features in the Seoul dialect. Articulatory state is postulated based on previous research and the main findings of the current study.

\begin{tabular}{|c|c|c|c|}
\hline & Acoustic correlate & Aerodynamic correlate & Postulated articulatory state \\
\hline Fortis & $\begin{array}{l}\text { Shortest VOT } \\
\text { Intermediate fo } \\
\text { Small or negative H1-H2 }\end{array}$ & $\begin{array}{l}\text { Low rate of airflow }\left(\mathrm{U}_{0}\right) \\
\text { High oral pressure }(\mathrm{Po}) \text {, but overlap with } \\
\text { the aspirated stop }\end{array}$ & $\begin{array}{l}\text { Small glottal opening (most constricted vocal folds) } \\
\text { Vocal folds tensed } \\
\text { Great subglottal pressure (Ps) } \\
\text { Creaky voice }\end{array}$ \\
\hline Lenis & $\begin{array}{l}\text { Intermediate VOT; but range overlap } \\
\quad \text { with the aspirated stop } \\
\text { Lowest fO } \\
\text { Intermediate H1-H2 }\end{array}$ & $\begin{array}{l}\text { Intermediate rate of airflow } \\
\text { Lowest oral pressure }\end{array}$ & $\begin{array}{l}\text { Larger glottal opening than the fortis stop, but similar } \\
\text { to that of the aspirated stop } \\
\text { Vocal folds least tensed } \\
\text { Smallest subglottal pressure } \\
\text { Close to modal voicing }\end{array}$ \\
\hline Aspirated & $\begin{array}{l}\text { Longest VOT; but range overlap with } \\
\text { the lenis stop } \\
\text { Highest fO } \\
\text { Greatest H1-H2 }\end{array}$ & $\begin{array}{l}\text { High rate of airflow } \\
\text { High oral pressure, but overlap with the } \\
\text { fortis stop }\end{array}$ & $\begin{array}{l}\text { Similar or larger glottal opening than the lenis stop } \\
\quad \text { (least constricted vocal folds) } \\
\text { Vocal folds more tensed than the fortis stop } \\
\text { Great subglottal pressure (PS) } \\
\text { Breathy voice }\end{array}$ \\
\hline
\end{tabular}

increase in the vocalis muscle activity before fortis stop release, and they consequently argued that this resulted in the increased tension of the vocal folds and constriction of the glottis during or after the fortis stop closure. Based on these results, Hirose et al. (1974) agree with the notion that fortis stops involve 'laryngealization' or 'glottalization'. In contrast, vocalis activity before the release of lenis stops did not show a transient increase, and unlike the aspirated stop, the suppression of the adductor muscles was not significant in the lenis stop. Table 10 shows the summary of reported patterns in previous aerodynamic and articulatory studies for the three Korean stops.

Tables 11 and 12 summarize the main findings of the current acoustic and aerodynamic study in the two dialects and show postulated articulatory states based on previous research (C.-W. Kim 1965, 1970; Kagaya 1974; Blankenship 2002; H. Kim et al. 2005) and the main findings of the current study. Based on these findings, possible phonological representations which can arrange these various phonetic dimensions in the two dialects will be presented in the next section.

\section{Phonological representation of Korean stops ${ }^{1}$}

The phonetic findings of the current study lead to the following questions:

\footnotetext{
${ }^{1}$ Insightful suggestions by an anonymous reviewer helped to formulate this section.
} 
Table 12 Summary of the main acoustic and aerodynamic features in the South Kyungsang dialect. Articulatory state is postulated based on previous research and the main findings of the current study.

\begin{tabular}{|c|c|c|c|}
\hline & Acoustic correlate & Aerodynamic correlate & Postulated articulatory state \\
\hline \multirow[t]{3}{*}{ Fortis } & Shortest VOT & Low rate of airflow (Uo) & Small glottal opening (constricted vocal folds) \\
\hline & $\begin{array}{l}\text { Intermediate f0, but overlap with the lenis } \\
\text { stop in HH and the aspirated stop } \\
\text { in LH pitch pattern }\end{array}$ & $\begin{array}{l}\text { High oral pressure (Po), but overlap } \\
\text { with the aspirated stop }\end{array}$ & $\begin{array}{l}\text { Vocal folds tensed, particularly in the high } \\
\text { tone condition, but the tenseness is } \\
\text { similar to the lenis stop in HH pattern }\end{array}$ \\
\hline & Small or negative H1-H2 & & Creaky voice \\
\hline \multirow[t]{3}{*}{ Lenis } & $\begin{array}{l}\text { Intermediate VOT } \\
\text { Low fO, but overlap with the fortis in LH } \\
\text { pitch pattern }\end{array}$ & $\begin{array}{l}\text { Intermediate rate of airflow, but overlap } \\
\text { with the fortis stop }\end{array}$ & $\begin{array}{l}\text { Larger glottal opening than the fortis stop } \\
\text { (less constricted vocal folds than the } \\
\text { fortis stop) }\end{array}$ \\
\hline & $\begin{array}{l}\text { Intermediate H1-H2; but overlap with the } \\
\text { aspirated stop in LH pitch pattern }\end{array}$ & Lowest oral pressure & $\begin{array}{l}\text { Vocal folds less tense, especially in the low } \\
\text { tone condition }\end{array}$ \\
\hline & & & Close to modal voicing \\
\hline \multirow[t]{3}{*}{ Aspirated } & Longest VOT & High rate of airflow & Largest glottal opening \\
\hline & $\begin{array}{l}\text { Highest fO in the HH pattern; but overlap } \\
\text { in fO with the fortis in HH pattern }\end{array}$ & $\begin{array}{l}\text { High oral pressure, but overlap with } \\
\text { the fortis stop }\end{array}$ & $\begin{array}{l}\text { Vocal folds tensed } \\
\text { Breathy voice }\end{array}$ \\
\hline & $\begin{array}{l}\text { Greatest H1-H2; but overlap with the lenis } \\
\text { in LH pitch pattern }\end{array}$ & & \\
\hline
\end{tabular}

Table 13 Laryngeal features of Korean stops proposed by Halle \& Stevens (1971) based on C.-W. Kim's $(1965,1970)$ acoustic findings.

\begin{tabular}{lllll}
\hline & Phonological features & Fortis & Lenis & Aspirated \\
\hline Glottal width & Spread glottis & - & + & + \\
\multirow{4}{*}{ Tension of vocal folds } & Constricted glottis & - & - & - \\
& Stiff vocal folds & + & - & + \\
& Slack vocal folds & - & - & - \\
\hline
\end{tabular}

- How can phonological features represent the distinctive Korean stops?

- How can the differences in the phonetic realization in the two dialects be specified by phonological features?

In this section, the phonological representation of Korean stops in the two dialects is suggested based on previous approaches (Halle \& Stevens 1971, Cho et al. 2002) and the phonetic findings in this study.

Halle \& Stevens (1971) investigated the featural specification of voicing, aspiration, and glottalization and suggested a phonological system of Korean stops based on the acoustic findings by C.-W. Kim $(1965,1970)$ shown in Table 13.

Halle \& Stevens (1971) proposed the binary features [ \pm Spread Glottis] and $[ \pm$ Constricted Glottis] to specify obstruents. Moreover, they indicated that the features [ \pm Stiff Vocal Folds] and $[ \pm$ Slack Vocal Folds] are appropriate to capture the distinction among the voiceless stops. The Korean fortis stop for which the glottis is neither constricted nor spread was specified as [-Spread Glottis, -Constricted Glottis]. In addition, based on the acoustic finding by C.-W. Kim (1965) that f0 after the fortis or aspirated stop tends to increase, the feature of [+Stiff, -Slack Vocal Folds] was suggested. As for the lenis and the aspirated stop, Halle \& Stevens (1971) mentioned that not only fully aspirated stops (e.g. Hindi stops) but also the moderately aspirated Korean stop (compare the lenis stop) are specified as [+Spread Glottis, -Constricted Glottis]. Moreover, unlike the aspirated or the fortis stop which is specified as [+Stiff, -Slack Vocal Folds] because of its higher f0 at vowel onset, Halle \& Stevens (1971) suggested [-Stiff, 
-Slack Vocal Folds] for the lenis stop, but [-Stiff, +Slack Vocal Folds] for the lenis stop in intervocalic position.

Cho et al. (2002) discussed that two-way or even three-way contrastive stops in other languages (e.g. English, Thai) could be successfully specified in terms of the categories [voiced], [voiceless unaspirated] and [aspirated] with the VOT values as phonetic realization. However, Cho et al. (2002) also noted that this categorization was not applicable to Korean stops, which has a three-way contrast only in the voiceless region. First, Cho et al. (2002) argue that when Korean stops are categorized only in terms of VOT, the four categories [voiced], [voiceless unaspirated], [voiceless slightly aspirated] and [voiceless heavily aspirated] are inevitable. However, as stated in Cho et al. (2002: 222), this is redundant based on Keating's (1984) proposal that the three phonetic categories [voiced], [voiceless unaspirated] and [voiceless aspirated] express the maximum number of contrasts. Second, this categorization does not take into account any vowel correlates such as f0, and different phonation types (H1H2). Cho et al. (2002) turned their attention to Halle \& Stevens' (1971) featural specification of Korean stops: (i) $[ \pm$ Spread Glottis] and [ \pm Constricted Glottis], which reflect that the glottal width varies across stop categories, and (ii) $[ \pm$ Stiff Vocal Folds $]$ and $[ \pm$ Slack Vocal Folds], which characterize the tension of the vocal folds and other phonetic correlates related to the stops and the following vowel. However, Cho et al. (2002: 223) pointed out that 'a binary feature system, which categorizes the phonological features by the presence or absence of the features, cannot be applied to describe lenis stop voicing in word-medial position or neutral position of the vocal folds'. In other words, specifying the lenis stop as either [-Spread Glottis] or [+Spread Glottis] cannot reflect the intermediate position of the vocal folds and 'intervocalic lenis stop voicing phenomenon'. Hence, Cho et al. (2002) suggested that the privative feature system, which uses only two laryngeal features [Spread Glottis]/[Constricted Glottis] within the framework of underspecification theory (Lombardi 1991, 1995), is preferable to the binary feature system to specify the Korean stop categories. Cho et al. (2002) further argued that this reflects that the lenis stop is associated with a neutral position of the vocal folds and shows context-dependent laryngeal variation. Cho et al.'s suggestion is provided in (1).

$\begin{array}{ll}\text { (1) Fortis stop } & \text { [Constricted Glottis] } \\ \text { Aspirated stop } & \text { [Spread Glottis] } \\ \text { Lenis stop } & \text { unspecified }\end{array}$

(Cho et al. 2002: 224)

Now we can turn our attention to the phonetic findings in the current study for the phonological feature specification of Korean stops. With regard to the Seoul dialect, both of the acoustic properties of f0 and VOT showed a significant difference among the three laryngeal distinctions. In addition, further analysis showed that $\mathrm{f} 0$ as a single predictor classifies the three categories with 77\% accuracy, and VOT alone classifies Korean stops with $71.5 \%$ accuracy. This indicates that Seoul speakers use not only VOT but also f0 to distinguish the three laryngeal distinctions. As for the South Kyungsang dialect, the statistics reported that both VOT and f0 are also significant in distinguishing the three laryngeal distinctions, as in the Seoul dialect. However, one of the main findings is the different distribution of $\mathrm{f0}$ and VOT between the two dialects, which was revealed by significant interactions between Laryngeal Distinction and Dialect for both f0 and VOT. Specifically, f0 in the South Kyungsang dialect showed significant overlap among the three laryngeal distinctions, while f0 in Seoul did not; discriminant analysis also supported the unreliability of $\mathrm{f} 0$ as an acoustic cue for South Kyungsang speakers (classification accuracy: 54\%). Unlike the f0 distribution, however, South Kyungsang speakers showed well-separated VOT ranges (classification accuracy: 83\%), while Seoul dialect speakers had overlap between the lenis and aspirated stop. To sum up, although Seoul and South Kyungsang Korean use both VOT and f0 cues to distinguish the three-way 
Table 14 Proposed phonological features of Korean stops in Seoul and South Kyungsang Korean.

\begin{tabular}{lllll}
\hline & Tone & Tone specification & \multicolumn{2}{c}{ Feature specification } \\
\hline Aspirated & HH & [Upper] & [Spread Glottis] & [Stiff Vocal Folds] \\
& LH & [Lower] & & \\
\multirow{2}{*}{ Fortis } & HH & [Upper] & [Constricted Glottis] & [Stiff Vocal Folds] \\
& LH & [Lower] & & \\
Lenis & HH & [Upper] & Unspecified & [Slack Vocal Folds] \\
& LH & [Lower] & & \\
\hline
\end{tabular}

distinction among voiceless stops, the importance of each cue is different between the two dialects of Korean.

As suggested by a reviewer, to efficiently capture the phonological category with a unified feature specification regardless of the dialectal difference in phonetics, we first need to think what the shared phonetic property is for the Korean stops in the two dialects. Unlike f0, which is used for different purposes in the two dialects (i.e. stop distinction in Seoul; stop and lexical pitch distinction in Kyungsang), VOT, H1-H2 and airflow rate commonly capture the characteristics of the three-way distinction among the voiceless stops for both the non-tonal Seoul and tonal South Kyungsang dialects of Korean. This suggests that the phonological feature of [Spread Glottis]/[Constricted Glottis], which can be characterized with the phonetic measures VOT, H1-H2 or airflow, can be the primary feature for both dialects of Korean. Therefore, the current study adopts Lombardi's $(1991,1995)$ notion that Korean stops could be differentiated by the privative laryngeal features, primarily using [Spread Glottis]/[Constricted Glottis] features, closely following Cho et al. (2002). The lenis stop with phonetic realization of the intermediate VOT (neutral vocal fold position) is not assigned by any of the [Spread Glottis]/[Constricted Glottis] features. Under this account, the possible features will be as in Table 14 .

First, the underspecification rule with the features [Spread Glottis]/[Constricted Glottis] captures the VOT and airflow differences; [Spread Glottis] for long VOT, great intraoral airflow (Uo); [Constricted Glottis] for short VOT, low intraoral airflow (Uo), and Unspecified for the lenis stop, for neutral vocal fold position and intermediate intraoral airflow (Uo). In addition, the phonetic realization of $\mathrm{H} 1-\mathrm{H} 2$, an indicator of phonation type, can be accounted for by [Spread Glottis]/[Constricted Glottis]; [Spread Glottis] for breathy voice with a large $\mathrm{H} 1-\mathrm{H} 2$, and [Constricted Glottis] for creaky voice with a small or negative H1-H2. Second, under this account, the feature [Stiff Vocal Folds] can be predicted from either [Spread Glottis] or [Constricted Glottis] for the aspirated and the fortis stop, respectively. The unspecified lenis stop leads to the feature of [Slack Vocal Folds]. Third, in addition to the featural specification of the stops, we need to consider the difference in f0 space between the two dialects. For non-tonal Seoul Korean, the f0 space is expected to have two regions, specifying the stops with the features [Stiff Vocal Folds] for the aspirated and fortis stops or [Slack Vocal Folds] for the lenis stop. However, for the South Kyungsang dialect, the lexical pitch accent dialect, we may expect that the f0 space of the phonological dimension is different from that of the Seoul dialect. For the tonal South Kyungsang Korean, the f0 realization in the initial syllable of the $\mathrm{HH}$ vs. LH contrast can be expressed by the [Upper]/[Lower] distinction. Kenstowicz \& Park (2006) suggested the four feature combinations that distribute f0 space to express both the lexical pitch and the three-way stop contrast in the South Kyungsang Korean: (i) upper - stiff vocal folds (HH-aspirated, HH-fortis); (ii) lower - stiff vocal folds (LH-aspirated, LH-fortis); (iii) upper - slack vocal folds (HH-lenis); and (iv) lower - slack vocal folds (LH-lenis). The current finding of an absolute f0 difference between the $\mathrm{HH}$ and $\mathrm{LH}$ pitch pattern and the fo distinction among the three stop contrasts also indicates the gradation of f0 space across the pitch accent and three-way stop distinction, supporting the four-way distinction of $\mathrm{f} 0$ in 
South Kyungsang Korean. In sum, underspecification theory (Lombardi 1991, 1995) provides a unified phonological account of the three-way distinction among Korean voiceless stops in both the Seoul and South Kyungsang dialects. The additional tone specification of [Upper] and [Lower] allows South Kyungsang to reflect f0 space for lexical pitch and stop contrast.

\section{General discussion}

This study has investigated the acoustic and aerodynamic properties of the well-known threeway distinction among Korean voiceless stops in two dialects, non-tonal Seoul Korean and tonal South Kyungsang Korean. Previous research by Kenstowicz \& Park (2006) examined the characteristics of the three laryngeal distinctions in Kyungsang dialects. However, the comparison between Seoul and Kyungsang dialects was made on the basis of Cho et al.'s (2002) study of Seoul Korean, and thus the role of dialect was evaluated based on numerical instead of statistical comparisons. Accordingly, the current study aimed to investigate the phonetic cues for the three-way contrast of Korean stops between the two dialects of Korean by using the same experimental procedure and conducting inferential statistics to directly compare the Korean stops in the two dialects.

In this study, we have identified several acoustic and aerodynamic factors that determine the three-way laryngeal distinction among Korean stops in the Seoul and South Kyungsang dialects. First, the two dialects use acoustic cues differently to distinguish the three-way stop contrast; Seoul speakers use a combination of f0 and VOT, while South Kyungsang speakers mainly rely on VOT. Second, Seoul speakers' tendency to use f0 as a primary acoustic cue instead of VOT seems to be related to a diachronic transition whereby VOT differences between the lenis and aspirated stops in Seoul Korean have been decreasing over the past 50 years. Third, South Kyungsang speakers indeed make the tonal distinction between High and. Low. The significant overlap in f0 distributions among stops, particularly between the Low tone fortis and the High tone lenis stop, suggests that the presence of lexical pitch accent in South Kyungsang makes fo an unreliable acoustic cue for the Korean stop distinction. Since Kyungsang speakers are already using fo to distinguish tonal contrasts, the use of fo for the purpose of classifying the three laryngeal distinctions seems to be diminished. Finally, the results of the aerodynamic study not only replicated previous findings, but also made it possible to postulate the differences in articulation between the two dialects along with the acoustic findings.

There are two issues remaining for further research. First, as a reviewer mentioned, although the pitch accent in Kyungsang Korean has three patterns in disyllabic words (HH, HL, LH), only two patterns, $\mathrm{HH}$ and $\mathrm{LH}$, were tested in the present study. Future research including all three pitch patterns in Kyungsang Korean will be able to provide a more detailed picture of the relationship between tone and segments by observing the difference between $\mathrm{HH}$ and HL as well as HH and LH. Second, it will be of interest to test if the acoustically observed dialectal variation in the use of VOT and f0 in the three stops also shows up perceptually. This will link acoustics to perception, and thus ultimately lead to a comprehensive phonetic model regarding not only the three-way distinction among Korean voiceless stops, but the relationship between tone and segments as well.

\section{Acknowledgements}

We would like to thank Joan Sereno and Jie Zhang for insightful comments and careful guidance at all stages of this work. We are grateful to the students in the Empirical Research course for their helpful discussion and feedback. Our thanks also go to JIPA editor Adrian Simpson and three anonymous 
reviewers for their valuable comments. An earlier version of this work was presented at the 159th meeting of the Acoustical Society of America in Baltimore, Maryland.

\section{References}

Ahn, Hyunkee. 1999. Post-release phonatory processes in English and Korean: Acoustic correlates and implications for Korean phonology. Ph.D. dissertation, The University of Texas at Austin.

Atkinson, James E. 1978. Correlation analysis of the physiological factors controlling fundamental voice frequency. Journal of the Acoustical Society of America 63, 211-222.

Blankenship, Barbara. 2002. The timing of nonmodal phonation in vowels. Journal of Phonetics 30(2), 193-228.

Boersma, Paul \& David Weenink. 2007. Praat: Doing phonetics by computer (Version 4.3.22). http:// www.Praat.org/.

Cho, Taehong. 1996. Vowel correlates to consonant phonation: An acoustic-perceptual study of Korean obstruents. MA thesis, The University of Texas at Arlington.

Cho, Taehong, Sun-Ah Jun \& Peter Ladefoged. 2002. Acoustic and aerodynamic correlates of Korean stops and fricatives. Journal of Phonetics 30, 193-228.

Choi, Hansook. 2002. Acoustic cues for the Korean stop contrast: Dialectal variation. ZAS Papers in Linguistics 28, 1-12.

Dart, Sarah N. (1987) An aerodynamic study of Korean stop consonants: Measurements and modeling. Journal of the Acoustical Society of America 81(1), 138-147.

Halle, Morris \& Kenneth N. Stevens. 1971. A note on laryngeal features. Quarterly Progress Report (Research Laboratory of Electronics, MIT 101), 198-212.

Han, Mieko S. \& Ray S. Weitzman. 1970. Acoustic features of Korean /P, T, K/, /p, t, k/ and /p $\mathrm{p}^{\mathrm{h}}, \mathrm{t}^{\mathrm{h}}, \mathrm{k}^{\mathrm{h}} /$. Phonetica 22, 112-128.

Hanson, Helen M. 1995. Glottal characteristics of female speakers. Ph.D. dissertation, Harvard University.

Hirose, Hajime, Charles Y. Lee \& Tatsujiro Ushijima. 1974. Laryngeal control in Korean stop production. Journal of Phonetics 2, 145-152.

Hombert, Jean-Marie \& Peter Ladefoged. 1977. The effect of aspiration on the fundamental frequency of the following vowel. UCLA Working Papers in Phonetics 36, 33-40.

Iseli, Markus \& Abeer Alwan. 2004. An improved correction formula for the estimation of harmonic magnitudes and its application to open quotient estimation. The Institute of Electrical and Electronics Engineers International Conference on Acoustics, Speech, and Signal Processing 1, 669-672.

Kagaya, Ryohei. 1974. A fiberscopic and acoustic study of the Korean stops, affricates and fricatives. Journal of Phonetics 2, 161-180.

Kang, Kyoung-Ho \& Susan G. Guion. 2008. Clear speech production of Korean stops: Changing phonetic targets and enhancement strategies. Journal of the Acoustical Society of America 124(6), 3909-3917.

Keating, Patricia A. 1984. Phonetic and phonological representation of stop consonant voicing. Language 60, 286-319.

Keating, Patricia A. \& Christina [M.] Esposito. 2007. Linguistic voice quality. UCLA Working Papers in Phonetics 105, 85-91.

Kenstowicz, Michael \& Chiyoun Park. 2006. Laryngeal features and tone in Kyungsang Korean: A phonetic study. Studies in Phonetics, Phonology and Morphology 12(2), 247-264.

Kim, Chin-Wu. 1965. On the autonomy of the tensity feature in stop classification. Word 21, 339-359.

Kim, Chin-Wu. 1970. The theory of aspiration. Phonetica 21, 107-116.

Kim, Hyunsoon, Kiyoshi Honda \& Shinji Maeda. 2005. Stroboscopic-cine MRI study of the phrasing between the tongue and the larynx in the Korean three-way phonation contrast. Journal of Phonetics $33,1-26$.

Kim, Mi-Ryoung, Patrice S. Beddor \& Julie Horrocks. 2002. The contribution of consonantal and vocalic information to the perception of Korean initial stops. Journal of Phonetics 30, 77-100.

Kim, Mi-Ryoung \& San Duanmu. 2004. 'Tense' and 'lax' stops in Korean. Journal of East Asian Linguistics 13, 59-104. 
Lai, Yuwen. 2004. The effect of aspiration on the fundamental frequency of the following tone in Taiwanese. MA thesis, University of Kansas.

Lee, Charles Y. \& Timothy S. Smith. 1972. Oral and direct subglottal pressure in Korean stops. Journal of the Acoustical Society of America 51(1A), 102-102.

Lieberman, Philip \& Sheila E. Blumstein. 1988. Speech physiology, speech perception, and acoustic phonetics. Cambridge: Cambridge University Press

Lisker, Leigh \& Arthur Abramson. 1964. Cross-language study of voicing in initial stops: Acoustical measurements. Word 20, 384-422.

Lombardi, Linda. 1991. Laryngeal features and laryngeal neutralization. Ph.D. dissertation, University of Massachusetts Amherst.

Lombardi, Linda. 1995. Laryngeal features and privativity. The Linguistic Review 12, 35-59.

Park, Hansang. 2002. Temporal and spectral characteristics of Korean phonation types. Ph.D. dissertation, The University of Texas at Austin.

Ramsey, Samuel R. 1975. Accent and morphology in Korean dialects: A descriptive and historical study. Ph.D. dissertation, Yale University.

Repp, Bruno H. 1983. Trading relations among acoustic cues in speech perception are largely a result of phonetic categorization. Speech Communication 2(4), 341-361.

Shipp, Thomas \& Robert E. McGlone. 1971. Laryngeal dynamics associated with voice frequency change. Journal of Speech and Hearing Research 14, 761-767.

Silva, David J. 2006. Acoustic evidence for the emergence of tonal contrast in contemporary Korean. Phonology 23, 287-308.

Wayland, Ratree \& Allard Jongman. 2003. Acoustic correlates of breathy and clear vowels: The case of Khmer. Journal of Phonetics 31, 181-201. 